\title{
Attraction and Repellent Behaviors of Culicoides Biting Midges toward Cow Dung, Carbon Dioxide, and Essential Oils
}

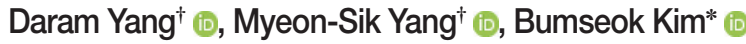 \\ College of Veterinary Medicine and Biosafety Research Institute, Jeonbuk National University, Iksan 54596, Korea
}

\begin{abstract}
Culicoides biting midges (Diptera: Ceratopogonidae) are hematophagous arthropod vectors that transmit epizootic arthropod-borne viruses (arboviruses). Arboviruses are recognized as causes of pregnancy loss, encephalomyelitis, and congenital malformations in ruminants. Therefore, continuous monitoring and control of Culicoides, which causes significant damage to industrial animals are necessary. We performed attraction and repellent tests in Culicoides using various essential oils, cow dung, and carbon dioxide $\left(\mathrm{CO}_{2}\right)$. Culicoides tended to move more to cow dung $(60.8 \%$, $P<0.0001)$ and $\mathrm{CO}_{2}(63.8 \%, P<0.01)$. To the essential oils as repellents, $26.1 \%(P<0.0001), 18.7 \%(P<0.001)$, and $25.5 \%(P<0.01)$ of the Culicoides moved to the lavender, lemongrass, and eucalyptus chamber, respectively. The Culicoides that moved to the 3 essential oils chambers showed markedly low activity. Collectively, it was showed that Culicoides tended to be attractive to cow dung and $\mathrm{CO}_{2}$, and repellent from the 3 essential oils.
\end{abstract}

Key words: Culicoides, biting midge, essential oil, attraction, repellent

\section{INTRODUCTION}

Culicoides biting midges (Diptera: Ceratopogonidae) are the smallest blood-sucking arthropods and their length rarely exceeds $3 \mathrm{~mm}$ [1]. The wings of adult Culicoides display various patterns by species, which can be useful for classifying the species [2]. Culicoides are vectors that transmit epizootic arthropod-borne viruses (arboviruses) such as the Akabane virus, the bovine ephemeral fever, the bluetongue virus, and the Schmallenberg virus to livestock $[1,3,4]$. Arboviruses are major pathogens in the veterinary field and ruminants infected with arboviruses have a high fever, reduced appetite, respiratory abnormalities, and salivation. Also, the infections cause abortion, stillbirth, and congenital malformation in the fetus, resulting in a significant economic loss in the industrial animal field [5]. Culicoides has a wide range of activities across the globe, and sporadic outbreaks of the disease are serious international problems. Therefore, constant monitoring and control of Culicoides should be required.

- Received 8 April 2021, revised 3 August 2021, accepted 29 September 2021.

*Corresponding author (bskims@jbnu.ac.kr)

${ }^{\dagger}$ These authors contributed equally to this work.

(c) 2021, Korean Society for Parasitology and Tropical Medicine

This is an Open Access article distributed under the terms of the Creative Commons Attribution Non-Commercial License (https://creativecommons.org/licenses/by-nc/4.0) which permits unrestricted non-commercial use, distribution, and reproduction in any

medium, provided the original work is properly cited.
Many previous studies have been conducted to control mosquitoes of various species that cause direct damage to humans. Aedes aegypti, as a representative example, is known as a vector of not only Zika virus but also dengue fever and yellow fever viruses [6-8]. Aedes aegypti is widely distributed around the world because they are easily adaptable to a variety of environments, and many studies have been conducted on test substances that could be used to develop control methods. One bioactivity study using plant essential oils suggested that the leaf and bark essential oils of Camellia japonica were an effective larvicide against Aedes aegypti [9]. A previous study by Gillij et al. [10] proposed conditions that showed the most effective repellent activity against Aedes aegypti using aromatic plant essential oils of different species and concentrations. Other studies have also demonstrated that ammonia and carbon dioxide $\left(\mathrm{CO}_{2}\right)$ were attractants of Aedes aegypti [11,12]. These studies were conducted on mosquitoes such as Culex pipiens molestus and Anopheles stephensi, not just on Aedes aegypti, and many mosquito repellents have been developed based on the results $[13,14]$.

Few attractions or repellent tests have been conducted on Culicoides, which causes significant damage to industrial animals currently. Therefore, we developed a useful device that can be used to investigate the attraction and repellent tendencies of Culicoides and performed attraction and repellent tests 
using essential oils, cow dung, and $\mathrm{CO}_{2}$.

\section{MATERIALS AND METHODS}

\section{Collection of Culicoides biting midges}

Culicoides biting midges were collected using a CDC black light trap (SNC, Hanam, Korea) from June to August in cattle

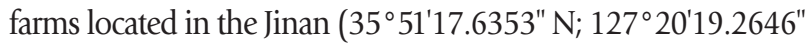
E) area, Jeonbuk Province, where the most Culicoides were collected in the previous study [15]. The light trap consisted of an $8 \mathrm{~W}$ ultraviolet fluorescent light and had a downdraft suction fan at the bottom. The trap chamber had 4 attachment holes for connecting to the branching chambers. The diameter of branching chamber was $9 \mathrm{~cm}$ and height was $7 \mathrm{~cm}$ except test material space. Additionally, the branching chamber was divided into an upper space and a lower space by a mesh membrane that prevents Culicoides from touching with the test substances. The diameter of bridge passage was $2 \mathrm{~cm}$ and length was $5 \mathrm{~cm}$. The lid holes were closed during collection. The trap was set up in the afternoon before dark and removed the next morning after sunrise.

\section{Preparation of test substances}

Cow dung and $\mathrm{CO}_{2}$ were used as potential attractant substances for Culicoides. The fresh cow dung (50 g) was obtained on the day of Culicoides collection, and a dry ice block (about $2 \mathrm{~cm}^{3}$ ) was used as the $\mathrm{CO}_{2}$ source [16]. To effectively spread $\mathrm{CO}_{2}, 50 \mathrm{ml}$ of distilled water (DW) was added to a dry ice block shortly before the test.

Three pure (100\%) essential oils (lavender, lemongrass, and eucalyptus) were purchased from NOW Food (Bloomingdale, Illinois, USA). Each was formulated as a $0.2 \%$ solution (v/v, $100 \mu \mathrm{l}$ of essential oil in $50 \mathrm{ml}$ of DW).

\section{Movement test of Culicoides biting midges}

We made in-house a specially designed mobile chamber to investigate the movement of Culicoides (Korean Patent No. 10$2141006,2018)$ [17]. It consisted of a trap chamber where $\mathrm{Cu}$ licoides were collected and 4 branching chambers in which test material could be placed (Fig. 1A). When collected Culicoides, the trap chamber was brought to the laboratory, test material was put into 2 branching chambers, and DW into the other 2 branching chambers as controls (Fig. 1B). The whole chamber was placed in a dark room for 30 min until the Culicoides moved sufficiently.

After 30 min, each branching chamber was detached from the trap chamber, and frozen for at least $5 \mathrm{hr}$ (Fig. 1C). The Culicoides species among the insects in each chamber were identified under a dissecting microscope and counted $[15,18]$.

The test was repeated 3 times per test substance. The results of each test were calculated to average and presented as the means with standard deviation. The attraction and repellent percentage were calculated in 2 ways using the following formulas. A was the total number of collected Culicoides and B was the total number of Culicoides moved to the test substance. $\mathrm{C}$ was the total number of Culicoides moved to DW.
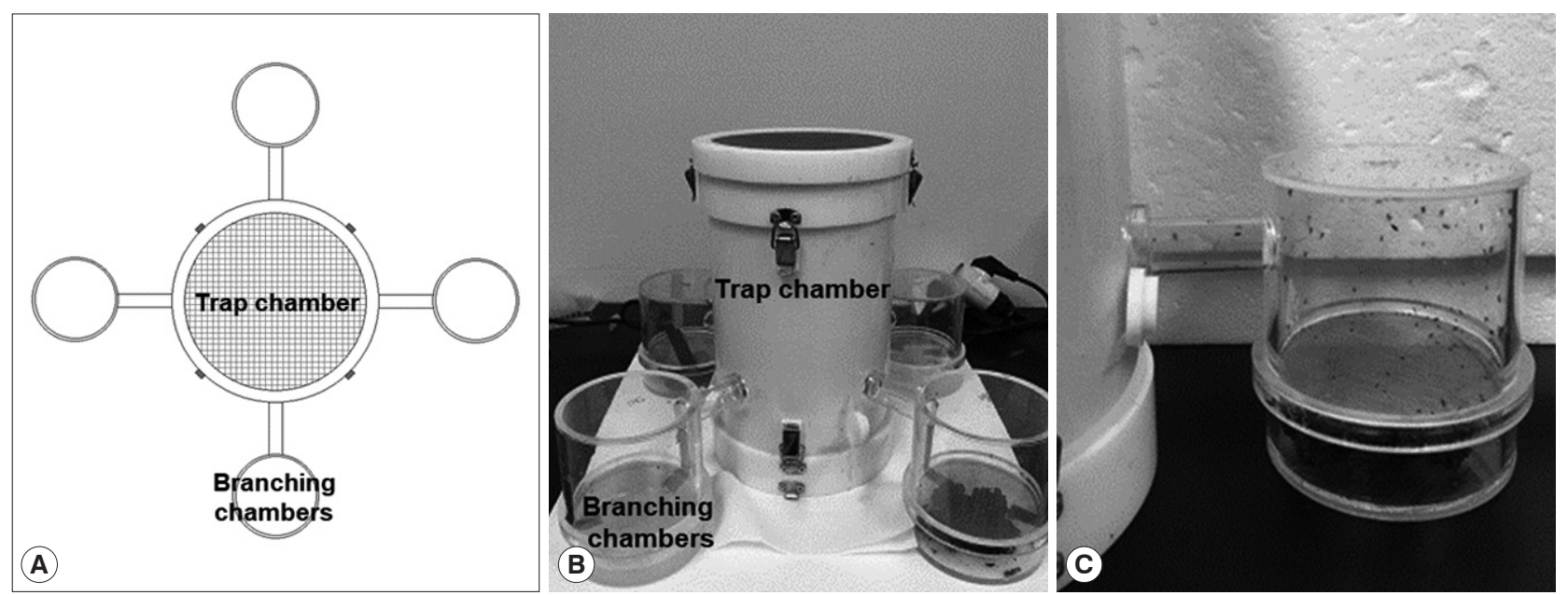

Fig. 1. Diagram and picture of the device for Culicoides movement test. The device for the Culicoides attraction or repellent tests consisted of a main trap chamber and 4 branching chambers (A, B). Culicoides were collected in the trap chamber and allowed to move to the branching chambers containing each test substance $(C)$. 
In compared to total collected number,

$$
\text { Attraction or repellent } \%=\left(\frac{B}{A}\right) \times 100
$$

In compared to only control group except for no moved,

$$
\text { Attraction or repellent } \%=\left(\frac{B}{B+C}\right) \times 100
$$

\section{Statistical analysis}

The differences between each group were compared with a 2-tailed t-test using Prism version 7.04 (GraphPad Software, San Diego, California, USA). A P value $<0.05$ was considered to be statistically significant.

\section{RESULTS}

\section{Attraction of Culicoides to cow dung or $\mathrm{CO}_{2}$}

In the cow dung group, $59.6 \pm 6.8 \%(n=164,98$, and 153$)$ of the total collected Culicoides did not move, $24.6 \pm 3.8 \%$ $(\mathrm{n}=49,48$, and 72$)$ moved to the cow dung chamber, and $15.8 \pm 3.0 \%$ ( $n=30,31$, and 48 ) moved to the DW chamber (Fig. 2A). As a result of comparing the movement rate between DW and cow dung, a mean of $60.8 \%(P<0.0001)$ of the Culicoides moved to the cow dung chamber and a mean of $39.2 \%$ moved to the DW chamber.

In the $\mathrm{CO}_{2}$ group, $45.6 \pm 10.3 \%(\mathrm{n}=62,50$, and 65$)$ of the Culicoides stayed in the trap chamber without movement,
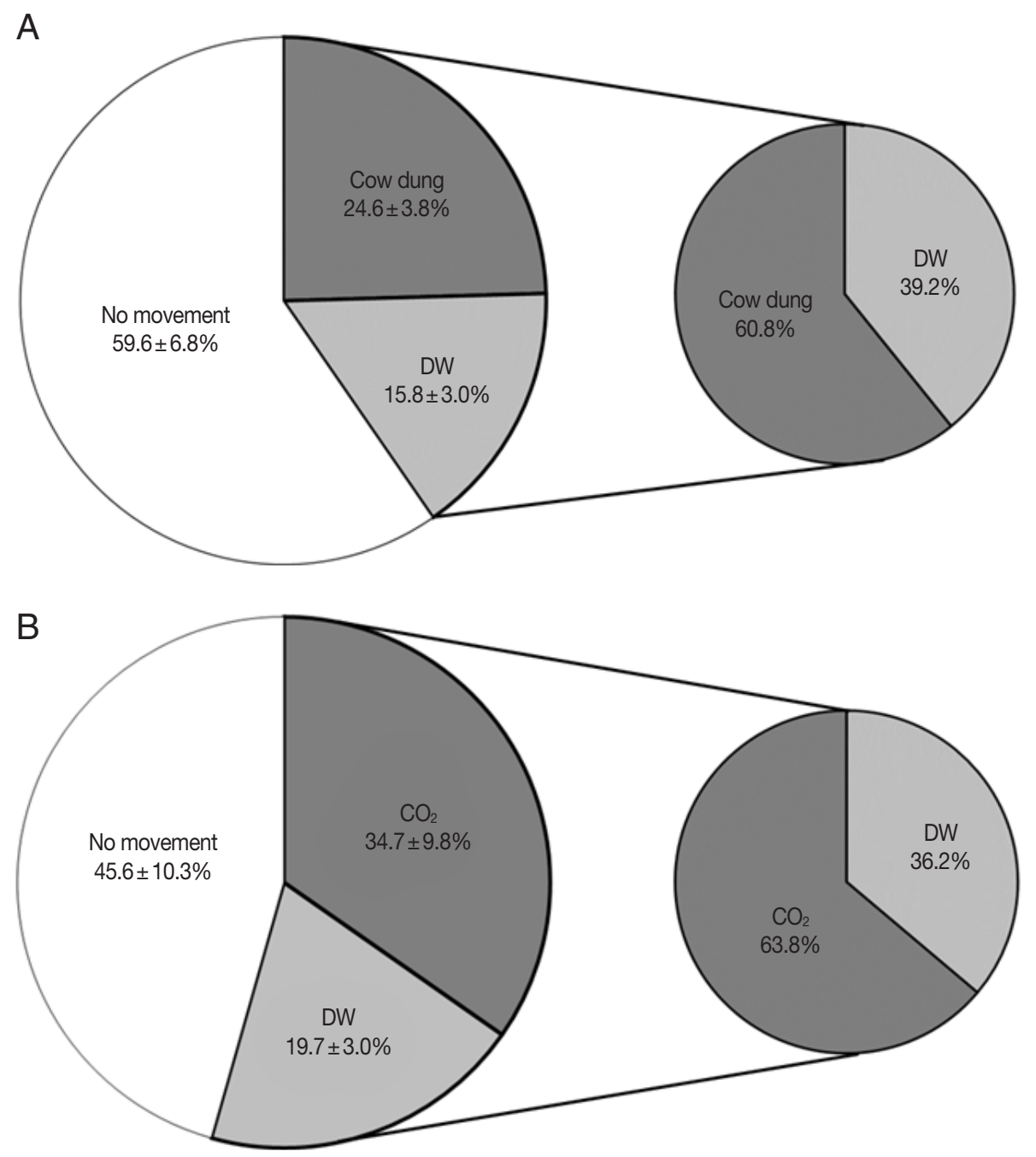

Fig. 2. Mean movement rates of Culicoides to cow dung or carbon dioxide $\left(\mathrm{CO}_{2}\right)$ compared to the total collected number or DW. Of the total collected Culicoides, $24.6 \pm 3.8 \%$ moved to cow dung group $(A)$, and a mean of $60.8 \%(P<0.0001)$ of the moved Culicoides moved to cow dung group compared to the DW group. Among the total collected Culicoides, $34.7 \pm 9.8 \%$ moved to the $\mathrm{CO}_{2}$ group (B), and a mean of $63.8 \%(P<0.01)$ of the moved Culicoides moved to $\mathrm{CO}_{2}$ group compared to the DW group. 
$34.7 \pm 9.8 \%(\mathrm{n}=78,37$, and 30$)$ moved to the $\mathrm{CO}_{2}$ chamber, and $19.7 \pm 3.0 \%(\mathrm{n}=32,26$, and 20$)$ moved to the DW chamber (Fig. 2B). Excluding the Culicoides that did not move, a mean of $63.8 \%(P<0.01)$ of the Culicoides moved to the $\mathrm{CO}_{2}$ chamber and $36.2 \%$ moved to the DW chamber.

Culicoides tended to move to cow dung (1.6 times) and $\mathrm{CO}_{2}$ (1.8 times) more than DW and showed more active movement to $\mathrm{CO}_{2}$ than to cow dung.

\section{Repellent behavior of Culicoides to essential oils}

In the lavender oil group, $80.1 \pm 4.2 \%(n=475,444$, and 440) of the collected Culicoides did not move but $14.7 \pm 2.8 \%$ $(\mathrm{n}=96,60$, and 95$)$ moved to the DW chamber and $5.2 \pm$ $1.4 \%(\mathrm{n}=34,19$, and 36$)$ moved to the lavender oil chamber (Fig. 3A). A mean of 73.9\% among the moved Culicoides moved to the DW chamber and a mean of $26.1 \%(P<0.0001)$ moved to the lavender oil chamber.

In the lemongrass oil group, $77.2 \pm 2.7 \%(n=403,209$, and 198) of the collected Culicoides did not move but $18.5 \pm 2.4 \%$ $(\mathrm{n}=81,58$, and 48$)$ moved to the DW chamber and $4.3 \pm$ $1.6 \%(\mathrm{n}=26,15$, and 6$)$ moved to the lemongrass oil chamber (Fig. 3B). Comparing the movement rate between DW and lemongrass oil, a mean of $81.3 \%$ moved to the DW chamber but a mean of $18.7 \%(P<0.001)$ moved to the lemongrass oil chamber.

Lastly, in the eucalyptus oil group, $72.2 \pm 8.1 \%(\mathrm{n}=141$, 130, and 255) of the collected Culicoides stayed in the trap chamber without movement, but $20.7 \pm 4.2 \%(\mathrm{n}=45,47$, and $50)$ moved to the DW chamber and $7.1 \pm 4.6 \%(n=10,25$, and 12) moved to the eucalyptus oil chamber (Fig. 3C). Excluding the Culicoides that did not move, a mean of $74.5 \%$ moved to the DW chamber, and a mean of $25.5 \%(P<0.01)$ moved to the eucalyptus oil chamber.

The movement of Culicoides based on 3 essential oils showed that about $76.6 \pm 4.0 \%$ of the total collected Culicoides did not move at all, and a few Culicoides moved to lavender, lemongrass, and eucalyptus oil at $5.2 \pm 1.4 \%, 4.3 \pm 1.6 \%$, and $7.1 \pm 4.6 \%$, respectively. In addition, the Culicoides that moved to the 3 essential oil chambers showed markedly low activity.

\section{DISCUSSION}

Previous studies have conducted attraction or repellent tests using various essential oils and components in mosquitoes that directly attack humans such as the Culex and Aedes genera.
We focused on the significance of Culicoides in the industrial animal field and conducted tests specific to Culicoides. In this study, Culicoides tended to prefer $\mathrm{CO}_{2}$ and cow dung more than DW, the control group. Dense breeding of a large number of ruminants in a small space reduces the activity radius of the animal and increases the temperature inside the farms, which can generate a large amount of $\mathrm{CO}_{2}$ by increasing the respiration rate. To prevent intensive access to Culicoides, it is necessary to maintain a pleasant environment by appropriately controlling the number of livestock in a particular breeding ground. In addition, regular cleaning of cow dung may reduce the spread of ammonia, which mosquitoes prefer. This study was evaluated by excluding the characteristics of Culicoides biting midge that exist in various habitats depending on species [1]. Therefore, it seems that more efficient prevention is possible if the attraction behavior test according to species is investigated.

Investigations of the attraction or repellent tendencies of mosquitoes using test substances have been conducted in a variety of ways. Newhouse et al. [19] compared the number of mosquitoes collected by installing light traps with or without dry ice at the same time. Several studies have evaluated the efficacy of test substances by counting the number of bites after applying a test substance or control substance directly to the human forearm or mouse skin [20-22]. However, it may be difficult to obtain a constant result in an outdoor environment using these methods and it is hard to rear mosquitoes in the laboratory. In our study, we developed a convenient device for conducting Culicoides collection and attraction or repellent tests at the same time. It is possible to directly investigate attraction or repellent tendencies by connecting the branching chambers containing the test substance on the collection day, without transferring the Culicoides that are collected. The concentration of the test substance should be high enough to allow Culicoides to notice it and move. In this study, we initially had used essential oils at concentration of $1 \%$. That concentration was too high to test because the scent spread even to the control chamber and Culicoides did not move to any chamber. Therefore, the experiment was carried out by modifying the final concentration to $0.2 \%$ through a concentration-determining experiment. As indicated above, proper concentration settings are important and the conditions suitable for the experiment should be established. Additionally, many Culicoides did not move even though the appropriate concentration was used. It is thought that they did not move simply because they 

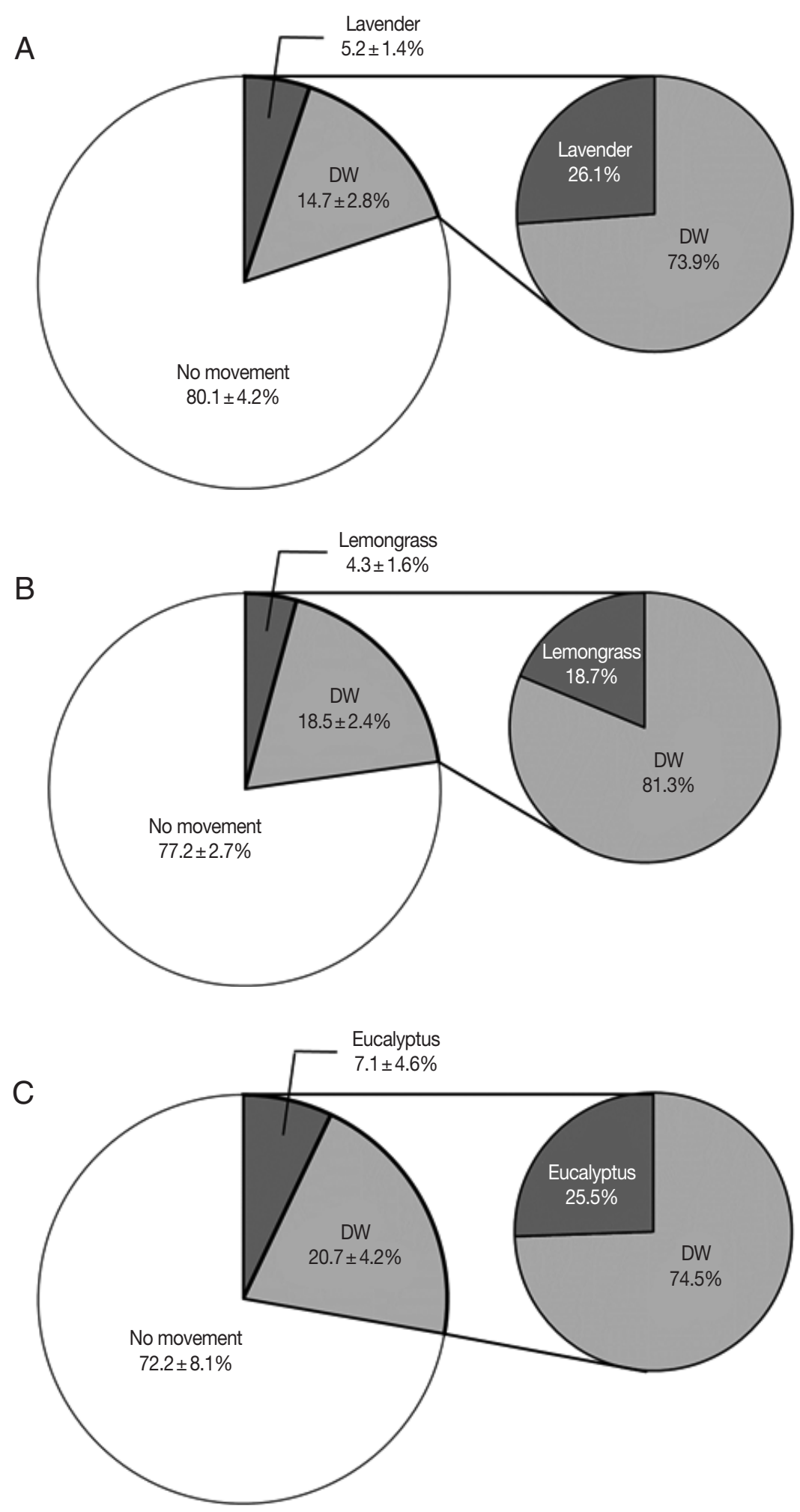

Fig. 3. Mean movement rates of Culicoides to 3 essential oils compared to the total collected number or DW. Only a few Culicoides moved to lavender (A), lemongrass (B), and eucalyptus (C) group at $5.2 \pm 1.4 \%, 4.3 \pm 1.6 \%$, and $7.1 \pm 4.6 \%$, respectively. Compared to the DW group, a mean of $26.1 \%(P<0.0001), 18.7 \%(P<0.001)$, and $25.5 \%(P<0.01)$ moved to lavender, lemongrass, and eucalyptus group, respectively. 
stayed in the unfamiliar environment. Comparing the Culicoides immobility rate between the attraction and the repellent behavior test, the percentage was larger in the repellent test than in the attraction test. It is thought that the immobility rate in the repellent test may be higher than that in the attraction behavior test because Culicoides did not prefer the odor of essential oils. In the attraction behavior test using a substance preferred by Culicoides, it is supposed that the movement rate was higher than in the repellent test since they were more likely to recognize the odor and moved to test substance actively.

Due to the toxicity and environmental risk of $\mathrm{N}, \mathrm{N}$-diethylm-toluamide (DEET), the most effective and widely used insect repellent [23,24], the development of harmless natural repellents for humans and animals is increasing. This study confirmed that lavender, lemongrass, and eucalyptus essential oils have repellent effects on Culicoides. Plant-derived natural essential oils are harmless when applied to human skin with proper condition (concentration, ratio, or $\mathrm{pH}$ ) [25-27]. Even for natural materials, it is important to use with a dose that does not cause irritation or side effects when applied to humans or animals. Since these are only a few of the essential oils known to have mosquito repellent effects, we expect that further research can be conducted on the repellent effects of various essential plant oils. The development of non-toxic natural repellents using essential oils that have been found to have repellent effects against Culicoides will effectively prevent Culicoides access and the spread of epizootic diseases.

\section{ACKNOWLEDGMENTS}

This work was supported by the Co-operative Research Program for Agriculture, Science and Technology Development (PJ011978072017) in the Rural Development Administration, Republic of Korea and was supported by the Basic Science Research Program through the National Research Foundation of Korea (NRF) funded by the Ministry of Education (2019 R1A6A1A03033084).

\section{CONFLICT OF INTEREST}

The authors declare that there are no conflicts of interest.

\section{REFERENCES}

1. Mellor PS, Boorman J, Baylis M. Culicoides biting midges: their role as arbovirus vectors. Annu Rev Entomol 2000; 45: 307-340. https://doi.org/10.1146/annurev.ento.45.1.307

2. Venegas P, Pérez N, Zapata S, Mosquera JD, Augot D, Rojo-Álvarez JL, Benítez D. An approach to automatic classification of Culicoides species by learning the wing morphology. PLoS One 2020; 15: e0241798. https://doi.org/10.1371/journal.pone.0241798

3. Carpenter S, Wilson A, Mellor PS. Culicoides and the emergence of bluetongue virus in northern Europe. Trends Microbiol 2009; 17: 172-178. https://doi.org/10.1016/j.tim.2009.01.001

4. Elbers AR, Meiswinkel R, van Weezep E, van OldruitenborghOosterbaan MMS, Kooi EA. Schmallenberg virus in Culicoides spp. biting midges, the Netherlands, 2011. Emerg Infect Dis 2013; 19: 106. https://doi.org/10.3201/eid1901.121054

5. Parsonson I, Della-Porta A, Snowdon W. Congenital abnormalities in newborn lambs after infection of pregnant sheep with Akabane virus. Infect Immun 1977; 15: 254-262. https://doi.org/ 10.1128/iai.15.1.254-262.1977

6. Nene V, Wortman JR, Lawson D, Haas B, Kodira C, Tu ZJ, Loftus B, Xi Z, Megy K, Grabherr M, Ren Q, Zdobnov EM, Lobo NF, Campbell KS, Brown SE, Bonaldo MF, Zhu J, Sinkins SP, Hogenkamp DG, Amedeo P, Arensburger P, Atkinson PW, Bidwell S, Biedler J, Birney E, Bruggner RV, Costas J, Coy MR, Crabtree J, Crawford M, Debruyn B, Decaprio D, Eiglmeier K, Eisenstadt E, El-Dorry H, Gelbart WM, Gomes SL, Hammond M, Hannick LI, Hogan JR, Holmes MH, Jaffe D, Johnston JS, Kennedy RC, Koo H, Kravitz S, Kriventseva EV, Kulp D, Labutti K, Lee E, Li S, Lovin DD, Mao C, Mauceli E, Menck CF, Miller JR, Montgomery P, Mori A, Nascimento AL, Naveira HF, Nusbaum C, O'leary S, Orvis J, Pertea M, Quesneville H, Reidenbach KR, Rogers YH, Roth CW, Schneider JR, Schatz M, Shumway M, Stanke M, Stinson EO, Tubio JM, Vanzee JP, Verjovski-Almeida S, Werner D, White O, Wyder S, Zeng Q, Zhao Q, Zhao Y, Hill CA, Raikhel AS, Soares MB, Knudson DL, Lee NH, Galagan J, Salzberg SL, Paulsen IT, Dimopoulos G, Collins FH, Birren B, Fraser-Liggett CM, Severson DW. Genome sequence of Aedes aegypti, a major arbovirus vector. Science 2007; 316: 1718-1723. https://doi.org/ 10.1126/science. 1138878

7. Kraemer MU, Sinka ME, Duda KA, Mylne AQ, Shearer FM, Barker CM, Moore CG, Carvalho RG, Coelho GE, Van Bortel W, Hendrickx G, Schaffner F, Elyazar IR, Teng HJ, Brady OJ, Messina JP, Pigott DM, Scott TW, Smith DL, Wint GR, Golding N, Hay SI. The global distribution of the arbovirus vectors Aedes aegypti and Ae. albopictus. Elife 2015; 4: e08347 https://doi.org/10.7554/ eLife.08347

8. Coates CJ, Jasinskiene N, Miyashiro L, James AA. Mariner transposition and transformation of the yellow fever mosquito, Aedes aegypti. Proc Natl Acad Sci USA 1998; 95: 3748-3751. https:// doi.org/10.1073/pnas.95.7.3748

9. Cheng SS, Chang HT, Chang ST, Tsai KH, Chen WJ. Bioactivity of selected plant essential oils against the yellow fever mosquito Aedes aegypti larvae. Bioresour Technol 2003; 89: 99-102. https:// doi.org/10.1016/s0960-8524(03)00008-7

10. Gillij Y, Gleiser R, Zygadlo J. Mosquito repellent activity of essential 
oils of aromatic plants growing in Argentina. Bioresour Technol 2008; 99: 2507-2515. https://doi.org/10.1016/j.biortech.2007.04.066

11. Geier M, Bosch OJ, Boeckh J. Ammonia as an attractive component of host odour for the yellow fever mosquito, Aedes aegypti. Chem Senses 1999; 24: 647-653. https://doi.org/10.1093/chemse/ 24.6.647

12. Majeed S, Hill SR, Ignell R. Impact of elevated CO2 background levels on the host-seeking behaviour of Aedes aegypti. J Exp Biol 2014; 217: 598-604. https://doi.org/10.1242/jeb.092718

13. Traboulsi AF, Taoubi K, El-Haj S, Bessiere JM, Rammal S. Insecticidal properties of essential plant oils against the mosquito $\mathrm{Cu}$ lex pipiens molestus (Diptera: Culicidae). Pest Manag Sci 2002;58: 491-495 https://doi.org/10.1002/ps.486

14. Prajapati V, Tripathi AK, Aggarwal KK, Khanuja SPS. Insecticidal, repellent and oviposition-deterrent activity of selected essential oils against Anopheles stephensi, Aedes aegypti and Culex quinquefasciatus. Bioresour Technol 2005; 96: 1749-1757. https://doi. org/10.1016/j.biortech.2005.01.007

15. Yang D, Yang MS, Rhim H, Han JI, Oem JK, Kim YH, Lee KK, Lim CW, Kim B. Analysis of five arboviruses and Culicoides distribution on cattle farms in Jeollabuk-do, Korea. Korean J Parasitol 2018; 56: 477-485. https://doi.org/10.3347/kjp.2018.56.5.477

16. Magnarelli L. Relative abundance and parity of mosquitoes collected in dry-ice baited and unbaited CDC miniature light traps. Mosq News 1975; 35: 350-353. https://www.biodiversitylibrary. org/content/part/JAMCA/MN_V35_N3_P350-353.pdf

17. Kim B, Yang D, Sung JJ, Shim KS, inventors; Jeonbuk National University, Assignee. Apparatus for examining the preference or repulsion tendency of mosquito on test material. Korean patent 10-2141006. 2018 Dec 10. 1-10 (in Korean). https://doi.org/10. $8080 / 1020180158153$

18. Cho HC, Chong CS. Notes on biting midges of the Genus Culicoides from South Korea-with special reference to unrecorded species and distribution. Korean J Parasitol 1974; 12: 45-75. http://doi. org/10.3347/kjp.1974.12.1.45

19. Newhouse VF, Chamberlain R, Johnston JG, Sudia WD. Use of dry ice to increase mosquito catches of the CDC miniature light trap. Mosq News 1966; 26: 30-35 https://www.biodiversitylibrary.org/content/part/JAMCA/MN_V26_N1_P030-035.pdf

20. Shirai Y, Kamimura K, Seki T, Morohashi M. L-lactic acid as a mosquito (Diptera: Culicidae) repellent on human and mouse skin. J Med Entomol 2001; 38: 51-54. https://doi.org/10.1603/0022-258538.1.51

21. Rutledge LC, Gupta RK, Wirtz RA, Buescher MD. Evaluation of the laboratory mouse model for screening topical mosquito repellents. J Am Mosq Control Assoc 1994; 10: 565-571. https:// core.ac.uk/download/pdf/21597505.pdf

22. Logan JG, Stanczyk NM, Hassanali A, Kemei J, Santana AE, Ribeiro KA, Pickett JA, Mordue AJ. Arm-in-cage testing of natural human-derived mosquito repellents. Malar J 2010; 9: 239. https://doi.org/10.1186/1475-2875-9-239

23. Koren G, Matsui D, Bailey B. DEET-based insect repellents: safety implications for children and pregnant and lactating women. CMAJ 2003; 169: 209-212. https:/www.cmaj.ca/content/cmaj/169/3/209. full.pdf

24. Weeks JA, Guiney PD, Nikiforov AI. Assessment of the environmental fate and ecotoxicity of N, N-diethyl-m-toluamide (DEET). Integr Environ Assess Manag 2012; 8: 120-134. https://doi.org/ 10.1002/ieam.1246

25. Jaenson TGT, Garboui S, PålssonK. Repellency of oils of lemon eucalyptus, geranium, and lavender and the mosquito repellent MyggA natural to Ixodes ricinus (Acari: Ixodidae) in the laboratory and field. J Med Entomol 2006; 43: 731-736. https://doi.org/ 10.1093/jmedent/43.4.731

26. Chattopadhyay P, Dhiman S, Borah S, Rabha B, Chaurasia AK, Veer V. Essential oil based polymeric patch development and evaluating its repellent activity against mosquitoes. Acta Trop 2015; 147: 45-53. https://doi.org/10.1016/j.actatropica.2015.03.027

27. Semmler M, Abdel-Ghaffar F, Schmidt J, Mehlhorn H. Evaluation of biological and chemical insect repellents and their potential adverse effects. Parasitol Res 2014; 113: 185-188. https:// doi.org/10.1007/s00436-013-3641-7 
